OPEN ACCESS

Edited by:

Youngmee Kim,

Ewha Womans University,

South Korea

Reviewed by:

Catherine Raptopoulou, National Centre of Scientific Research

Demokritos, Greece

Suk Joong Lee,

Korea University, South Korea

*Correspondence:

Samar K. Das

skdsc@uohyd.ernet.in;

samar439@gmail.com

Specialty section:

This article was submitted to Colloidal Materials and Interfaces,

a section of the journal

Frontiers in Materials

Received: 19 March 2019 Accepted: 01 July 2019

Published: 17 July 2019

Citation:

Bommakanti S and Das SK (2019) A

Two-Dimensional

Metal-Organic-Framework Formed From a Cobalt(II) Ion and a Bifunctional

Ligand Exhibiting Thermochromic

Behavior. Front. Mater. 6:170

doi: 10.3389/fmats.2019.00170

\section{A Two-Dimensional Metal-Organic-Framework Formed From a Cobalt(II) Ion and a Bifunctional Ligand Exhibiting Thermochromic Behavior}

\author{
Suresh Bommakanti and Samar K. Das* \\ School of Chemistry, University of Hyderabad, Hyderabad, India
}

We have synthesized a two-dimensional metal organic framework (MOF) containing compound [ $\left.\mathbf{C o}_{0.5}^{\prime \prime}(\mathbf{H b p y d p})\left(\mathbf{H}_{\mathbf{2}} \mathbf{O}\right)\right]_{n} \cdot 2 n$ DMF $(\mathbf{1})$ by solvothermal synthesis. Compound 1 has been characterized by routine spectral analyses including elemental analysis and unambiguously by single crystal X-ray crystallography. In the crystal structure, the cobalt(II) ion is characterized by an octahedral geometry, which consists of two nitrogen donors from two different ligands, two oxygen donors from two different ligands and two water oxygen atoms. Thus, each cobalt has $\left\{\mathrm{CoO}_{4} \mathrm{~N}_{2}\right\}$ core octahedral moiety with all six donors coordinated in a monodentate fashion. This octahedral geometry of $\mathrm{Co}(\mathrm{II})$ in compound $\mathbf{1}$ is reflected by the characteristic orange coloration of compound $\mathbf{1}$ crystals. When the orange colored crystals of compound 1 are heated at $150^{\circ} \mathrm{C}$ under vacuum for $3 \mathrm{~h}$, the orange crystals become deep-purple in color indicating some structural change around $\mathrm{Co}(\mathrm{II})$ with the loss of two coordinated water molecules resulting in the formation of compound $\mathbf{2}\left\{\left[\mathbf{C o}_{0.5}^{\prime \prime}(\mathbf{H b p y d p})\right]_{n} \cdot \mathbf{2 n D M F}\right\}$ (2). The deep-purple solid (compound $\mathbf{2}$ ), on keeping in a water-DMF solvent mixture at an ambient condition for $15 \mathrm{~h}$ (rehydration), is converted back to orange solid again (this regenerated compound denoted as $\mathbf{1 R}$ ). This reversible conversion of 1-2 through $\mathbf{1 R}$ occurs in a crystal-to-amorphous-to-crystal (CAC) transformation. And the reversible thermochromism can be monitored by solid state electronic absorption spectroscopy (DRS) and thermogravimetric (TG) studies.

Keywords: metal-organic-framework, two-dimensional Co(II) coordination polymer, hydrothermal synthesis, self-assembly process, thermochromic behavior

\section{INTRODUCTION}

Metal-organic frameworks (MOFs) or coordination polymers (CPs) are the compounds formed by the self-assembly process of the metal nodes/clusters with multi-topic organic ligands. The intriguing structures and unique properties of these materials, achieved through the combination of organic and inorganic building units, make them functional materials for their diverse applications in different fields including catalysis (Dhakshinamoorthy et al., 2013; Chughtai et al., 2015), 
magnetism (Ryu et al., 2010; Mínguez Espallargas and Coronado, 2018; Mondal et al., 2018), sensing (Kreno et al., 2012; He et al., 2018), fuel cells (Hirayama et al., 2008; Ren et al., 2013), and electrochemistry (Manna et al., 2016). Compared to the traditional using of mixed-ligand systems (carboxylate and $\mathrm{N}$-linker) to fabricate these materials, the multifunctional ligands, such as, 3,5-dimethyl-1H-pyrazole-4carboxylic acid $\left(\mathrm{HMe}_{2} \mathrm{pzCO}_{2} \mathrm{H}\right)$ (Heering et al., 2013), 2,6-bis(pyrazol-1-yl)pyridine-4-carboxylic acid (bppCOOH) (GarcíaLópez et al., 2018; Bommakanti et al., 2019), amino-halo benzene dicarboxylates $\left(\mathrm{NH}_{2} \mathrm{X}-\mathrm{BDC}\right.$, where $\mathrm{X}=\mathrm{Cl}, \mathrm{Br}$, or I) (Kim et al., 2011), 4,4'-(4,4'-bipyridine-2,6-diyl)dibenzoic acid $\left(\mathrm{H}_{2}\right.$ bpydb) (Hou et al., 2010, 2017; Wei et al., 2013) etc., in which both functionalities present in a single ligand, offer diverse and interesting structural integrities.

In the recent years, the focus on the design and the construction of the new chromic organic-inorganic hybrid materials has increased due to their potential applications in the fields of sensors (thermo and chemical), display devices and non-linear optical (NLO) materials (Stavila et al., 2014). Generally, the chromism is associated with the reversible color change of the materials in response to the transformations occur in the corresponding materials. Depending on the external stimuli, which causes the color change in these materials, such as, light, temperature, pressure, and solvent molecules, they are categorized as photochromic (Pardo et al., 2011; Tandekar et al., 2018), thermochromic (Lim et al., 2018; Liu and Li, 2019), piezochromic (Dey et al., 2018), and solvatochromic materials (Lu et al., 2011; Mehlana et al., 2013), respectively. The investigation of the underlying mechanism for such sort of chromic behavior reveals that the color change is associated to the one of the following reasons: (i) charge transfer (CT)/electron transfer between the organic ligands [such as, 4,4-bipyridinium (Toma et al., 2015; Zhang et al., 2016), vialogen based ligands (Wan et al., 2015; Hu et al., 2017)] and the metal which changes their absorption properties, (ii) disruption of the interaction between the solvent molecules and the compounds which leads to the alterations in the crystal packing/supramolecular interactions (such as, hydrogen bonding, and $\pi \cdots \pi$ interactions), and (iii) coordination geometry transformations (Kundu et al., 2014; Burneo et al., 2015; Thapa et al., 2018) due to the loss of metal bound solvent molecules/rearrangement of the coordinating atoms around the metal centers.

Herein, we report the synthesis of a $\mathrm{Co}$ (II) based coordination compound $\left\{\mathrm{Co}_{0.5}^{\text {II }}(\mathrm{Hbpydp})\left(\mathrm{H}_{2} \mathrm{O}\right)\right\}_{\mathrm{n}} \cdot 2 n \mathrm{DMF}$ (1) using a bifunctional ligand, i.e., $\mathrm{H}_{2}$ bpydb $\left\{4,4^{\prime}\right.$-(4, $4^{\prime}$-bipyridine-2,6diyl)dibenzoic acid\} (see Scheme 1) and a secondary N-linker 3-BTA $\left\{\mathrm{N}, \mathrm{N}^{\prime}, \mathrm{N}^{\prime \prime}\right.$-tris(3-pyridyl)-1,3,5-benzenetricarboxamide\} under the hydrothermal conditions. The presence of the secondary ligand (3-BTA) is not observed in the crystal structure of compound 1, however, it plays a key role in the formation of single crystals of compound $\mathbf{1}$. The compound $\mathbf{1}$ is wellcharacterized by PXRD, IR, elemental and thermal analyses and unambiguously by the single crystal X-ray diffraction (SCXRD) studies. The SCXRD analysis reveals that the compound $\mathbf{1}$ forms a two-dimensional coordination network having an octahedral core of $\left\{\mathrm{CoO}_{4} \mathrm{~N}_{2}\right\}$, coordinated by the two oxygen and two nitrogen atoms from four different ligands and two water molecules. When compound 1 is heated at $150^{\circ} \mathrm{C}$ under the vacuum condition, it undergoes a structural change to form a dehydrated compound $\left\{\mathrm{Co}_{0.5}^{\text {II }}(\text { Hbpydp })\right\}_{n} \cdot 2 n \mathrm{DMF}$ (2). The resulting deep-purple colored compound 2, upon keeping in the water-DMF solvent mixture at room temperature, regenerates the parent compound (1R). However, during this reversible thermochromic process, the compound $\mathbf{1}$ undergoes structural transformation to form an amorphous substance 2 (loses its crystallinity), followed by regeneration of $\mathbf{1 R}$ in a reversible crystal-to-amorphous-to-crystal (CAC) transformation process. We, therefore, could not characterize the compound $\mathbf{2}$ unambiguously by single crystal X-ray crystallography, but it is characterized by the thermogravimetry (TG), UV-visible absorption spectroscopy, IR spectral analysis, and elemental analyses.

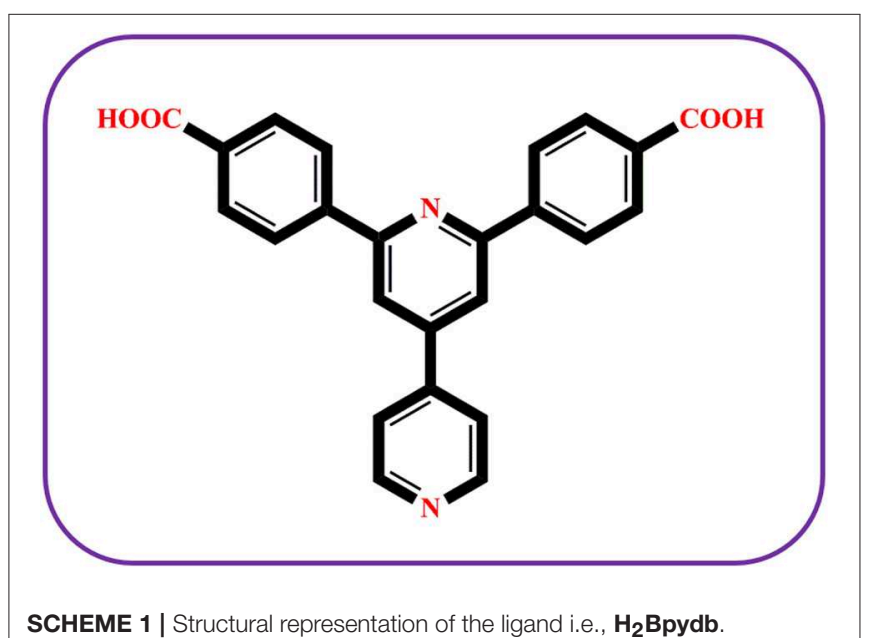

TABLE 1 | Crystal data and structure refinement parameters for compound 1

\begin{tabular}{|c|c|}
\hline & 1 \\
\hline Empirical formula & $\mathrm{C}_{30} \mathrm{H}_{31} \mathrm{Co}_{0.50} \mathrm{~N}_{4} \mathrm{O}_{7}$ \\
\hline Formula weight & 589.06 \\
\hline $\mathrm{T}(\mathrm{K}) / \lambda(\AA)$ & $293(2) / 1.54184$ \\
\hline Crystal system & Monoclinic \\
\hline Space group & $P 2_{1} / n$ \\
\hline$a(\AA)$ & $7.5930(3)$ \\
\hline$b(\AA)$ & $17.7114(4)$ \\
\hline$c(\AA)$ & $21.4805(6)$ \\
\hline$\alpha\left({ }^{\circ}\right)$ & 90 \\
\hline$\beta\left({ }^{\circ}\right)$ & $94.230(3)$ \\
\hline$\gamma\left({ }^{\circ}\right)$ & 90 \\
\hline Volume $\left(\AA^{3}\right)$ & $2880.89(15)$ \\
\hline$Z, \rho_{\text {calcd }}\left(\mathrm{g} \mathrm{cm}^{-3}\right)$ & $4,1.356$ \\
\hline$\mu\left(\mathrm{mm}^{-1}\right), F(000)$ & $2.949 / 1,230$ \\
\hline Goodness-of-fit on $\mathrm{F}^{2}$ & 1.032 \\
\hline 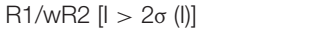 & $0.0602 / 0.1656$ \\
\hline R1/wR2 (all data) & 0.0788/0.1819 \\
\hline Largest diff peak/hole $\left(\mathrm{e} \AA^{-3}\right)$ & $0.504 /-0.320$ \\
\hline
\end{tabular}




\section{EXPERIMENTAL}

\section{Materials and Methods}

The metal source $\mathrm{CoCl}_{2} \cdot 6 \mathrm{H}_{2} \mathrm{O}$ and the $\mathrm{N}, \mathrm{N}$-dimethylformamide (DMF) solvent were purchased as a reagent grade and used without any further purification. The ligands $4,4^{\prime}-\left(4,4^{\prime}-\right.$ bipyridine-2,6-diyl)dibenzoic acid $\left(\mathrm{H}_{2}\right.$ bpydb) (Sharma et al., 2011) and $\mathrm{N}, \mathrm{N}^{\prime}, \mathrm{N}^{\prime \prime}$-tris(3-pyridyl)-1,3,5-benzenetricarboxamide (3-BTA) (Rajput and Biradha, 2011) were prepared according to the literature procedure. Elemental analyses were determined by using a FLASH EA series 1112 CHNS analyzer. Infrared spectra of solid samples were recorded as $\mathrm{KBr}$ pellets on a JASCO-5300 FT-IR spectrophotometer. Thermogravimetric analyses were carried out on an STA 409 PC under the flow of $\mathrm{N}_{2}$ gas at a heating rate of $10^{\circ} \mathrm{C} \mathrm{min}^{-1}$, in the temperature range of $30-600^{\circ} \mathrm{C}$. Powder X-ray diffraction patterns were recorded on a Bruker D8-Advance diffractometer using graphite monochromated $\mathrm{CuK} \alpha 1(1.5406 \AA)$ and $\mathrm{K} \alpha 2$ (1.54439 $\AA$ ) radiation. The title compound was synthesized hydrothermally in a $23 \mathrm{~mL}$ Teflon-lined stainless steel vessel (Thermocon, India). The electronic absorption spectra were recorded in the solid state on a UV-2600 Shimadzu UV-visible spectrophotometer at room temperature. Differential scanning calorimetry (DSC) thermal studies were carried out on a Pyris Diamond (Perkin-Elmer) instrument at a heating rate of $10^{\circ} \mathrm{C} / \mathrm{min}$.

\section{Synthesis}

Synthesis of $\left\{\mathrm{CoO}_{0.5} \mathrm{II}(\mathrm{Hbpydp})\left(\mathrm{H}_{2} \mathrm{O}\right)\right\}_{n} \cdot 2 n \mathrm{DMF}(1)$

A mixture of $\mathrm{CoCl}_{2} \cdot 6 \mathrm{H}_{2} \mathrm{O}$ (12 mg, $\left.0.05 \mathrm{mmol}\right), \mathrm{H}_{2}$ bpydb (19.82 mg, $0.05 \mathrm{mmol})$ and 3-BTA $(22 \mathrm{mg}, 0.05 \mathrm{mmol}$ ) was dissolved in a mixture of solvents $(8 \mathrm{~mL})$, i.e., water, DMF, and
A
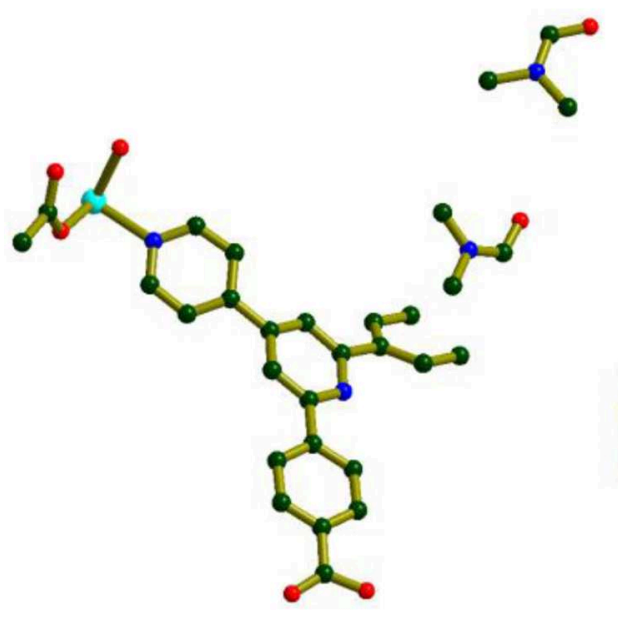

C

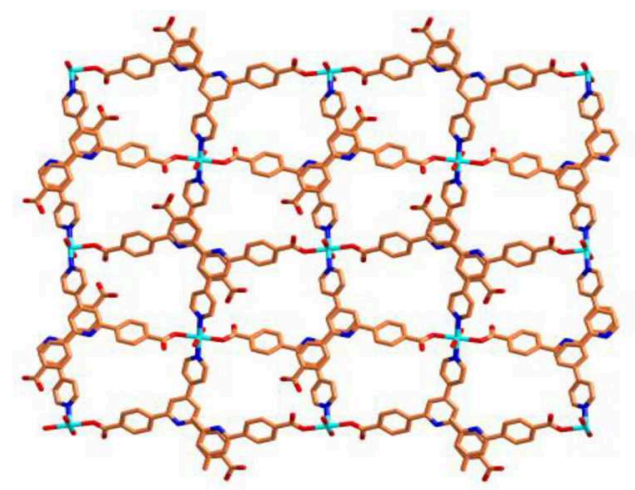

B

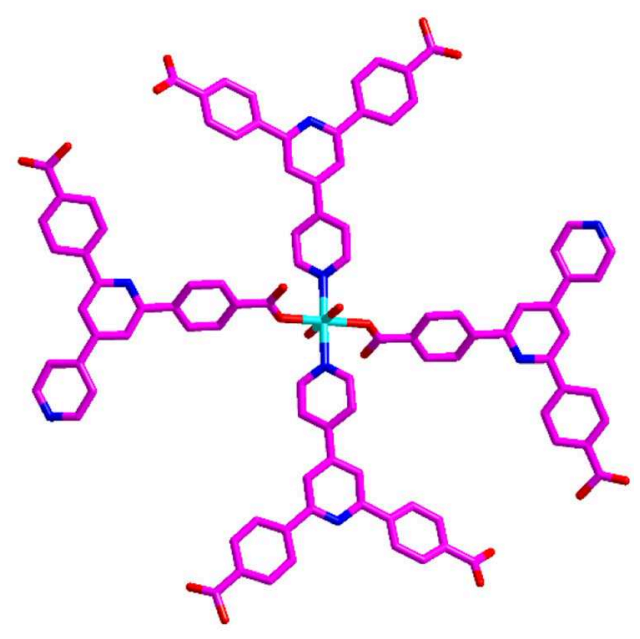

D

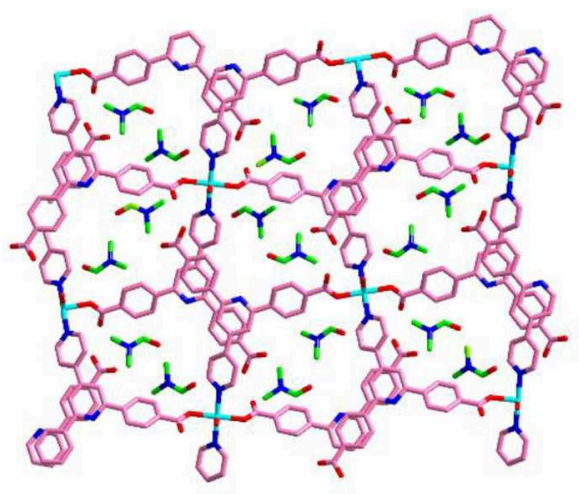

FIGURE 1 | (A) Asymmetric unit found in the crystal structure of compound 1 along with the two DMF and one water solvent molecules; hydrogen atoms are omitted for clarity. (B) Coordination environment surrounding the Co(II) metal ion. (C) 2D representation of compound $\mathbf{1}$ formed by the connectivity of the metal and $\mathrm{Hbpydb}{ }^{1-}$ ligand. (D) The overall structure of compound $\mathbf{1}$ including solvent DMF molecules. 
ethanol (2:4:2) and stirred for $30 \mathrm{~min}$. Then the reaction mixture $(\mathrm{pH} 3.25)$ was transferred to a stainless steel autoclave, sealed and heated to $120^{\circ} \mathrm{C}$ for $60 \mathrm{~h}$ to obtain orange crystals of 1 in $65 \%$ Yield (based on Co). Anal. Calcd for $\mathrm{C}_{60} \mathrm{H}_{62} \mathrm{CoN}_{8} \mathrm{O}_{14}(\mathrm{Mr}$ = 1,178.12): C, 61.17\%; H, 5.3\%; N, 9.51\%. Found: C, 61.85\%; H, 4.41\%; N, 9.48\% (Supplementary Figure 3). IR (KBr pellet, $\left.\mathrm{cm}^{-1}\right): 1,704,1,665,1,578,1,539,1,435,1,391,1,254,1,200,1,178$, 1,101, 1,019, 865, 772, 652 (Supplementary Figure 6).

\section{Synthesis of $\left\{\mathrm{Co}_{0.5}^{\prime \prime}(\mathrm{Hbpydp})\right\}_{\mathrm{n}} \cdot 2 \mathrm{nDMF}(2)$}

The orange colored single crystals of compound $\left\{\mathbf{C o}_{0.5}^{\text {II }}(\mathbf{H b p y d p})\left(\mathrm{H}_{2} \mathrm{O}\right)\right\}_{\mathbf{n}} \cdot \mathbf{2 n D M F}$ (1) were heated under vacuum at $150^{\circ} \mathrm{C}$ for $3 \mathrm{~h}$ to obtain deep-purple colored dehydrated compound $\quad\left\{\mathbf{C o}_{0.5}^{\text {II }}(\mathbf{H b p y d p})\right\}_{n} \cdot 2 n \mathrm{DMF} \quad$ (2). $\mathrm{C}_{60} \mathrm{H}_{58} \mathrm{CoN}_{8} \mathrm{O}_{12} \quad\left(M_{\mathrm{r}}=1142.09\right):$ C, 63.1\%; H, 5.12\%; N, 9.81\%. Found: C, 62.65\%; H, 4.92\%; N, $9.69 \%$ (Supplementary Figure 4). IR ( $\mathrm{KBr}$ pellet, $\left.\mathrm{cm}^{-1}\right): 1,688$, $1,587,1,534,1,381,1,232,1,177,1,106,1,068,1,013,862,822$, 780, 743, 699, 625 (Supplementary Figure 7).

\section{Synthesis of Regenerated Compound $\left\{\mathrm{Co}_{0.5}^{\mathrm{II}}(\mathrm{Hbpydp})\left(\mathrm{H}_{2} \mathrm{O}\right)\right\}_{\mathrm{n}} \cdot 2 n \mathrm{DMF}(1 \mathrm{R})$}

When the amorphous compound 2 was immersed in a water-DMF (8:2) solvent mixture for $15 \mathrm{~h}$, the color of this compound was observed to change from deep-purple to orange resulting in the formation of regeneration of parent material,

TABLE 2 | Hydrogen bond parameters $\left(\AA{ }^{\circ}{ }^{\circ}\right)$ in the supramolecular architecture of compound $\mathbf{1}^{\text {a }}$.

\begin{tabular}{lcccc}
\hline $\begin{array}{l}\text { Donor (D)-hydrogen } \\
\text { (H) } \cdots \text { Acceptor (A) }\end{array}$ & $\mathbf{d}(\mathbf{D}-\mathbf{H}) / \mathbf{A}^{\circ}$ & $\mathbf{d}(\mathbf{H} \cdots \mathbf{A}) / \mathbf{A}^{\circ}$ & $\mathbf{d}(\mathbf{D} \cdots \mathbf{A}) / \mathbf{A}^{\circ}$ & $\left.\angle(\mathbf{D}-\mathbf{H} \cdots \mathbf{A}) / \mathbf{(}^{\circ}\right)$ \\
\hline $\mathrm{O}(5)-\mathrm{H}(23) \cdots \mathrm{O}(6) \# 1$ & $0.80(4)$ & $1.95(4)$ & $2.747(4)$ & $176(4)$ \\
$\mathrm{O}(5)-\mathrm{H}(24) \cdots \mathrm{O}(2)$ & $0.75(4)$ & $2.03(4)$ & $2.727(4)$ & $155(4)$ \\
$\mathrm{C}(4)-\mathrm{H}(4) \cdots \mathrm{O}(7) \# 2$ & 0.93 & 2.50 & $3.332(6)$ & 149 \\
$\mathrm{C}(5)-\mathrm{H}(5) \cdots \mathrm{O}(6) \# 3$ & 0.93 & 2.55 & $3.275(5)$ & 135 \\
$\mathrm{C}(7)-\mathrm{H}(7) \cdots \mathrm{O}(7) \# 2$ & 0.93 & 2.55 & $3.463(6)$ & 168 \\
$\mathrm{C}(12)-\mathrm{H}(12) \cdots \mathrm{O}(7) \# 2$ & 0.93 & 2.57 & $3.500(6)$ & 175 \\
\hline
\end{tabular}

a Symmetry transformations used to generate equivalent atoms: \#1 $=2-x, 1-y,-z$, $\# 2=-1 / 2+x, 1 / 2-y, 1 / 2+z, \# 3=-3 / 2+x, 1 / 2-y, 1 / 2+z$. compound 1R. $\mathrm{C}_{60} \mathrm{H}_{62} \mathrm{CoN}_{8} \mathrm{O}_{14}(\mathrm{Mr}=1178.12)$ : C, $61.17 \%$; $\mathrm{H}, 5.3 \%$; N, 9.51\%. Found: C, 61.63\%; H, 5.38\%; N, 9.56\% (Supplementary Figure 5). IR ( $\mathrm{KBr}$ pellet, $\mathrm{cm}^{-1}$ ): 1,668, 1,589, $1,537,1,384,1,256,1,180,1,110,1,069,1,015,856,819,780,741$, 697, 666, 639, 578 (Supplementary Figure 8).

\section{Single Crystal X-Ray Structure Determination of Compound 1}

Data for the single crystals suitable for structural determination of compound 1 was collected on an Oxford Xcalibur Gemini Eos $\mathrm{CCD}$ diffractometer at $293 \mathrm{~K}$ using $\mathrm{Cu}-\mathrm{K} \alpha$ radiation $(\lambda=1.54184$ $\AA$ ). Data reduction was performed using CrysAlisPro (CrysAlis CCD and CrysAlis RED, Ver. 1.171.33.55; Oxford Diffraction Ltd: Yarnton, Oxfordshire, UK, 2008). Empirical absorption corrections using equivalent reflections were performed with the program SADABS (Sheldrick, 1997). Structure solutions were done by direct and Fourier methods using SHELXT (Sheldrick, 2015b) and refined by a full-matrix least-squares method using SHELXL (Sheldrick, 2015a) for the title compound. All the non-hydrogen atoms were refined anisotropically. Hydrogen atoms on the $\mathrm{C}$ atoms were introduced at calculated positions and were included in the refinement riding on their respective parent atoms. Crystal data and structure refinement parameters for compound $\mathbf{1}$ are summarized in Table $\mathbf{1}$, and the selected bond lengths and bond angles found in compound $\mathbf{1}$ are presented in Supplementary Table 1. CCDC 1903411 contains the supplementary crystallographic data for compound $\mathbf{1}$.

\section{RESULTS AND DISCUSSION}

\section{Description of Crystal Structure $\left\{\mathrm{Co}_{0.5}^{\prime \prime}(\mathrm{Hbpydp})\left(\mathrm{H}_{2} \mathrm{O}\right)\right\}_{n} \cdot 2 n D M F(1)$}

Compound 1 crystallizes in the monoclinic space group $P 2_{1} / n$ and the single crystal X-ray diffraction (SCXRD) analysis of this compound shows that, in the asymmetric unit of the compound 1, half of $\mathrm{Co}$ (II) metal center, one $\mathrm{Hbpydb}^{1-}$, one coordinated water molecule, and two lattice DMF molecules are present (Figure 1A). The Co(II) metal center, in the molecular unit of compound $\mathbf{1}$, is in an almost perfect octahedral geometry where it is coordinated with the two oxygen atoms of the two different "COO" groups of the two Hbpydb ${ }^{1-}$ ligands, two $\mathrm{N}$ atoms of the

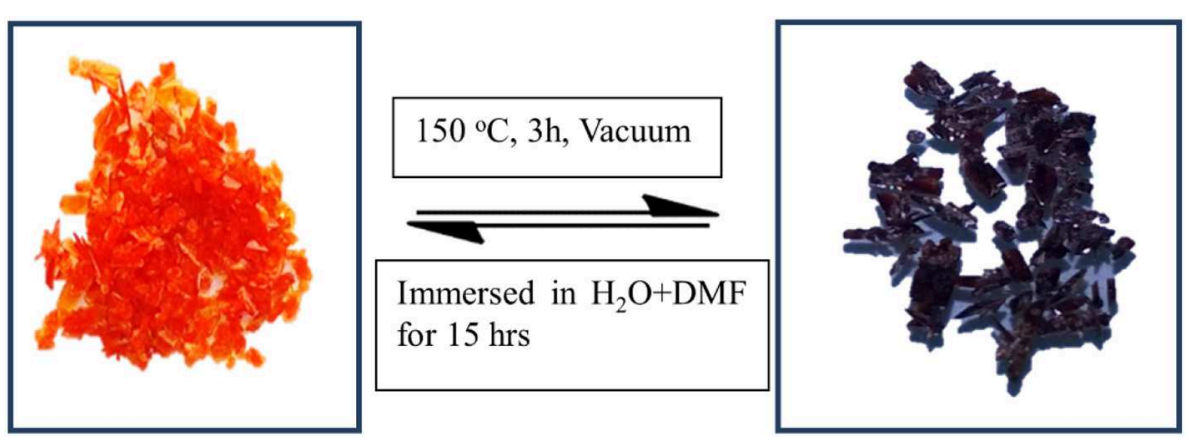

FIGURE 2 | Optical images of compound 1, (Left), and compound 2, (Right), clearly indicating a color change from orange to deep purple. 
pyridyl ring of the other two Hbpydb ${ }^{1-}$ ligands and two water molecules (Figure 1B). All the $\mathrm{Co}-\mathrm{O}$ bond distances are in the range of $2.086-2.120 \AA$ and the $\mathrm{Co}-\mathrm{N}$ bond distance is 2.147 $\AA$ A. Among the two "-COOH" groups and two pyridyl N atoms of one $\mathrm{H}_{2}$ bpydb ligand (see Scheme 1) only one "-COO" group and one pyridyl $\mathrm{N}$-atom are coordinated to the metal centers whereas the other "-COOH" group and pyridyl $\mathrm{N}$-atom remain uncoordinated. The "-COO" group of the Hbpydp" ${ }^{1-}$ ligand is coordinated to the Co(II) metal ion in a monodentate $\mu_{1}-\eta^{1}$ : $\eta^{0}$ coordination mode. Each $\mathrm{Co}$ (II) center is connected to the other four Co(II) centers by four Hbpydp ${ }^{1-}$ ligands resulting in the formation of a 2D framework (Figure 1C). Intramolecular $\pi \cdots \pi$ stacking interaction is observed between the phenyl ring of one Hbpydb ${ }^{1-}$ ligand and the uncoordinated pyridine ring of another $\mathrm{Hbpydb}^{1-}$ ligand. Figure 1D represents the overall structure of compound $\mathbf{1}$ including lattice solvent molecules. The crystal structure of compound $\mathbf{1}$ is found to be isostructural to the

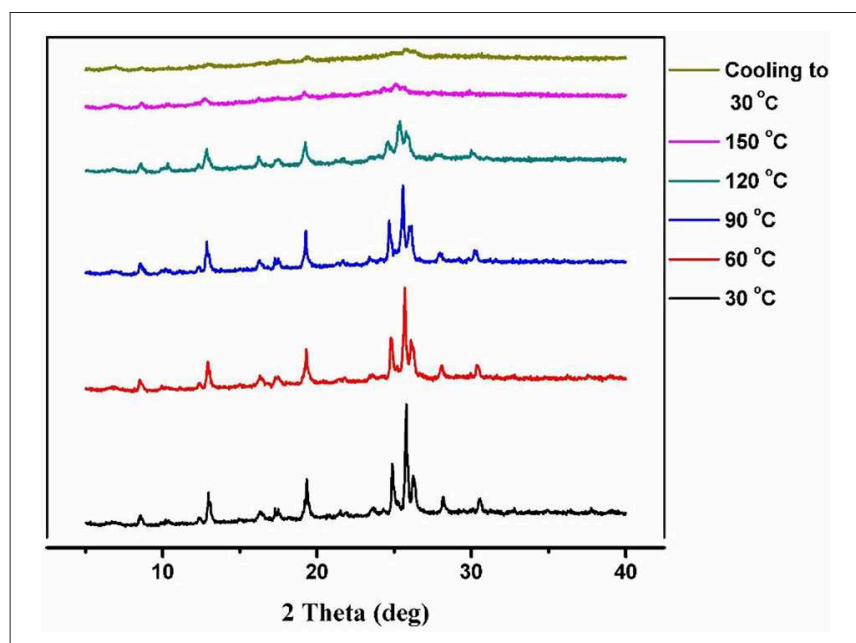

FIGURE 3 | Variable temperature PXRD patterns of compound $\mathbf{1 .}$ previously reported structures of $\mathrm{Ni}(\mathrm{II})$ and $\mathrm{Cu}(\mathrm{II})$ (Song et al., 2012; Sun et al., 2013). In the crystal structure of compound 1, the coordinated water molecules show classical hydrogen bonding interactions with one DMF molecule and one carboxylate oxygen of the Hbpydb ${ }^{1-}$ ligand, present in the 2D layer; the coordinated water molecule forms two hydrogen bonds: one with the DMF molecule (lattice solvent) $(\mathrm{O} 5-\mathrm{H} 23 \cdots \mathrm{O} 6)$ and the other one with the carboxylate oxygen (O5-H24‥O2) in the same 2D layer (Supplementary Figure 2a). In addition to these interactions, both the DMF molecules form nonclassical hydrogen bonding interactions with the $\mathrm{C}-\mathrm{H}$ moieties of phenyl rings, present in the corresponding ligand. The oxygen (O6) of one of the DMF molecule forms a $\mathrm{C}-\mathrm{H} \cdots \mathrm{O}$ interaction, whereas the other one $(\mathrm{O} 7)$ forms three such interactions: they are $\mathrm{C} 5-\mathrm{H} 5 \cdots \mathrm{O} 6, \mathrm{C} 4-\mathrm{H} 4 \cdots \mathrm{O} 7, \mathrm{C} 7-\mathrm{H} 7 \cdots \mathrm{O} 7$ and

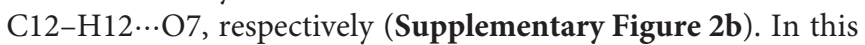
way, both the solvent molecules i.e., coordinated water and lattice DMF molecules exhibit non-covalent interactions within the same $2 \mathrm{D}$ layer rendering the compound $\mathbf{1}$ a two-dimensional supramolecular network. Crystal packing diagram of $\mathbf{1}$ can be seen in the Supplementary Figure 2c. Table 2 contains overall hydrogen bonding interaction parameters $\left(\AA,^{\circ}\right)$ involved in the formation of supramolecular architecture in the crystal structure of compound $\mathbf{1}$. The compound $\mathbf{2}$, which is obtained by heating the sample of $\mathbf{1}$ at $150^{\circ} \mathrm{C}$ for $3 \mathrm{~h}$ under the vacuum, loses its crystalline nature resulting in an amorphous material, and compound $\mathbf{1 R}$, which is regenerated by immersing the sample of 2 in water-DMF mixed solvent system for $15 \mathrm{~h}$, regains its crystalline phase during this period, which is reflected in their PXRD patterns (vide infra and also see Supplementary Figure 1).

\section{Reversible Thermochromic Behavior Mediated by Compound 1}

As described in the crystal structure, the $\mathrm{Co}(\mathrm{II})$ metal center in the molecular unit of compound $\mathbf{1}$, is present in an octahedral environment (Figure 1B), where the two opposite (apical)

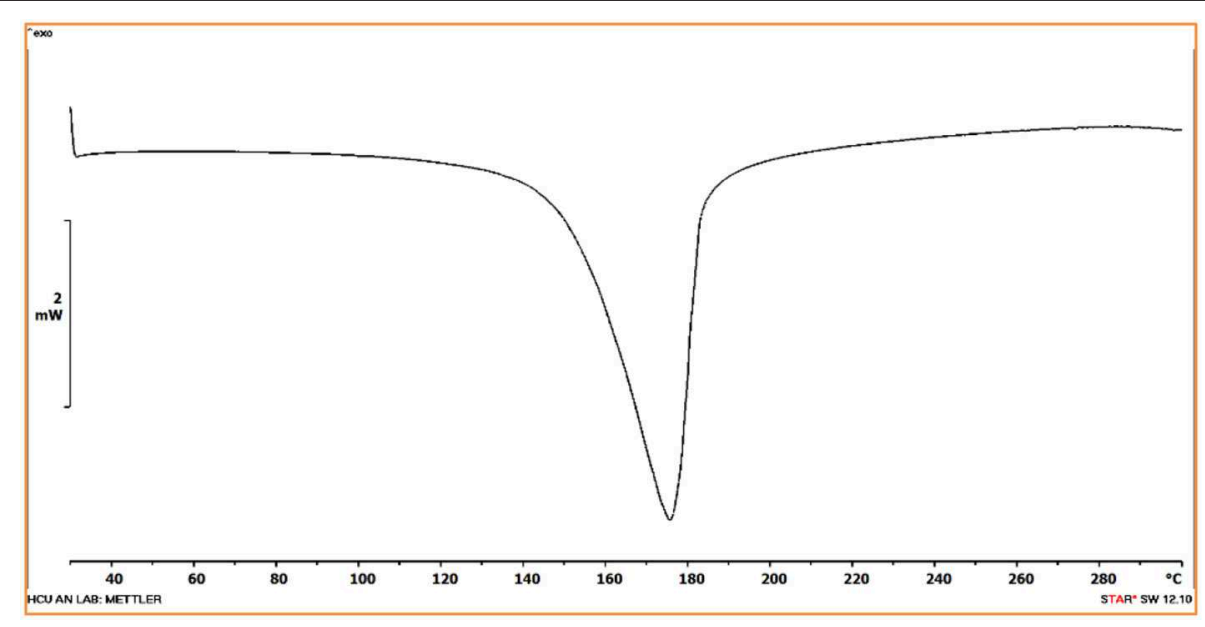

FIGURE 4 | Differential scanning calorimetry (DSC) of compound 1. 


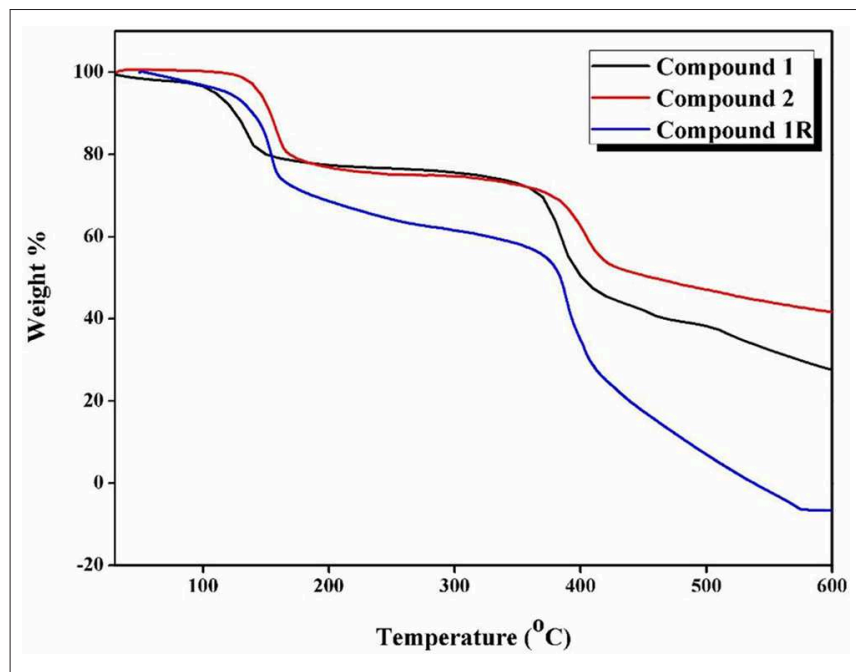

FIGURE 5 | Thermogravimetric curves of the compounds 1, 2, and $\mathbf{1 R}$.

coordination positions are occupied by the two water molecules forming $\left\{\mathrm{H}_{2} \mathrm{O}-\mathrm{Co}(\mathrm{II})-\mathrm{OH}_{2}\right\}$ moiety; the other four positions are coordinated by two nitrogen and two oxygen atoms of four $\mathrm{H}_{2}$ bpydb ligands. When the compound $\mathbf{1}$ crystals (orange color), are heated at $150^{\circ} \mathrm{C}$ for $3 \mathrm{~h}$ under the high vacuum, the color of the crystals is changed to deep-purple resulting in a dehydrated compound $\mathbf{2}$ as shown in Figure 2. In order to see any phase/structural transformations in $\mathbf{1}$ during this dehydration process, associated with color change, we measured the variable temperature powder X-ray diffraction (VT-PXRD) plots at various temperatures $\left(30,60,90,120\right.$, and $\left.150^{\circ} \mathrm{C}\right)$ at an interval temperature of $30^{\circ} \mathrm{C}$. As shown in Figure 3, the PXRD patterns of compound $\mathbf{1}$ reveal that the compound $\mathbf{1}$ remains unchanged in the temperature range of $30-120^{\circ} \mathrm{C}$ and does not show any phase transition; beyond this temperature, the compound, unfortunately, starts losing its crystallinity to result in an amorphous substance 2 . It can be anticipated, from this temperature dependent PXRD studies, that at $150^{\circ} \mathrm{C}$, the compound 1 (wherein $\mathrm{Co}(\mathrm{II})$ in an octahedral geometryorange compound), loses the two coordinated water molecules to result in a four-coordinated deep purple compound $\mathbf{2}$ as shown in Figure 2. This conversion process is also observed by the presence of an endothermic peak in the differential scanning calorimetry (DSC) analysis-plot (Figure 4). Compound 2 , an amorphous substance, could not be characterized by crystallography. Thus, compound $\mathbf{2}$ was characterized by IR, CHNS, TGA, and UV-DRS analyses. Based on these analyses, the formula of compound 2 has been deduced to be $\left\{\text { Co }_{0.5}^{\text {II }}(\text { Hbpydp })\right\}_{n} \cdot 2 n$ DMF (a dehydrated compound). The reversible nature of this transformation is observed when the compound 2 (deep-purple in color) is immersed in a water-DMF solvent mixture at room temperature for $15 \mathrm{~h}$ (for rehydration) resulting in a color change from deep-purple to orange. This rehydrated orange color compound, regained its crystallinity as observed by PXRD studies (Supplementary Figure 1), and showed identical IR, CHNS, TGA and UV-DRS data, as shown by parent compound $\mathbf{1}$ indicating the regeneration of compound 1 (the transformed rehydrated compound is denoted as $\mathbf{1 R}$ ). Interestingly, the compound 1, when kept in the water solvent alone/exposed to open atmosphere for 10-15 days, resulted in the original orange compound but in an amorphous phase, whereas in the water and DMF system resulted in a crystalline phase of $\mathbf{1}$. The formation of this crystalline phase in the presence of DMF reveals that this solvent has vital interactions with the framework in maintaining crystallinity in $\mathbf{1}$. Hence, the reversible conversion of compound $\mathbf{1}$ (crystalline phase) to $\mathbf{2}$ (amorphous) through $\mathbf{1 R}$ (crystalline phase), can be described to occur in a crystal-to-amorphous-to-crystal (CAC) transformation process. This kind of structural transformations (i.e., CAC) were reported in the literature (Tian et al., 2014; Hu et al., 2018). The TGA curve of the parent compound $\mathbf{1}$ shows a two-step degradation, where the first step is owing to the loss of water molecules, followed by the loss of DMF molecules in the second step. In contrast to this, compound $\mathbf{2}$ shows a single step degradation pertaining to the removal of DMF molecules, having a lack of water degradation step revealing the fact that the compound 2 is a dehydrated product. Moreover, the reversible nature can also be confirmed by the restoration of water loss step in the TGA plot of regenerated compound $\mathbf{1 R}$ (vide infra, TGA studies). The thermochromic behavior in this reversible crystal-to-amorphous-to-crystal (CAC) transformation process can be monitored by UV-visible spectroscopy (vide infra).

The compound $\mathbf{1}$ is also investigated for the photochromic as well as solvatochromic behavior; however, the compound $\mathbf{1}$ does not show any color change either (i) by the exposure of the crystals of compound $\mathbf{1}$ in sunlight even for 1 week or (ii) keeping it in different solvents e.g., in $\mathrm{MeOH}, \mathrm{DMF}, \mathrm{DMSO}$, $\mathrm{CHCl}_{3}$, acetone, $\mathrm{MeCN}$, etc.

\section{PXRD and Thermogravimetric Analysis (TGA)}

The phase purity of compound $\mathbf{1}$ has been ensured by recording its X-ray powder diffraction data. Similar diffraction patterns between the simulated data (calculated from SCXRD) and the experimental data confirm the bulk homogeneity of the compound $\mathbf{1}$. The compound $\mathbf{2}$ (dehydrated product of $\mathbf{1}$ ) is amorphous in nature, as evidenced by its PXRD pattern and the compound $\mathbf{1} \mathbf{R}$ (regenerated by immersing 2 in a mixed solvent system of water and DMF), retains the crystalline phase and shows a similar pattern to that of 1 (Supplementary Figure 1).

Thermal stability of all the compounds was ensured by thermogravimetric studies, performed under the nitrogen atmosphere from room temperature to $600^{\circ} \mathrm{C}$ on powdered samples at a heating rate of $10^{\circ} \mathrm{C} / \mathrm{min}$. The TGA curves of compounds 1, 2, and $\mathbf{1 R}$ reveal that these compounds are stable up to 145,155 , and $150^{\circ} \mathrm{C}$, respectively (Figure 5). In the first step of their TGA plots, compounds $\mathbf{1}$ and $\mathbf{1 R}$ (that are essentially identical) show the weight loss of 3.41 and $3.5 \%$, respectively, in the temperature range of $30-110^{\circ} \mathrm{C}$ that corresponds to the loss of the coordinated water molecules 

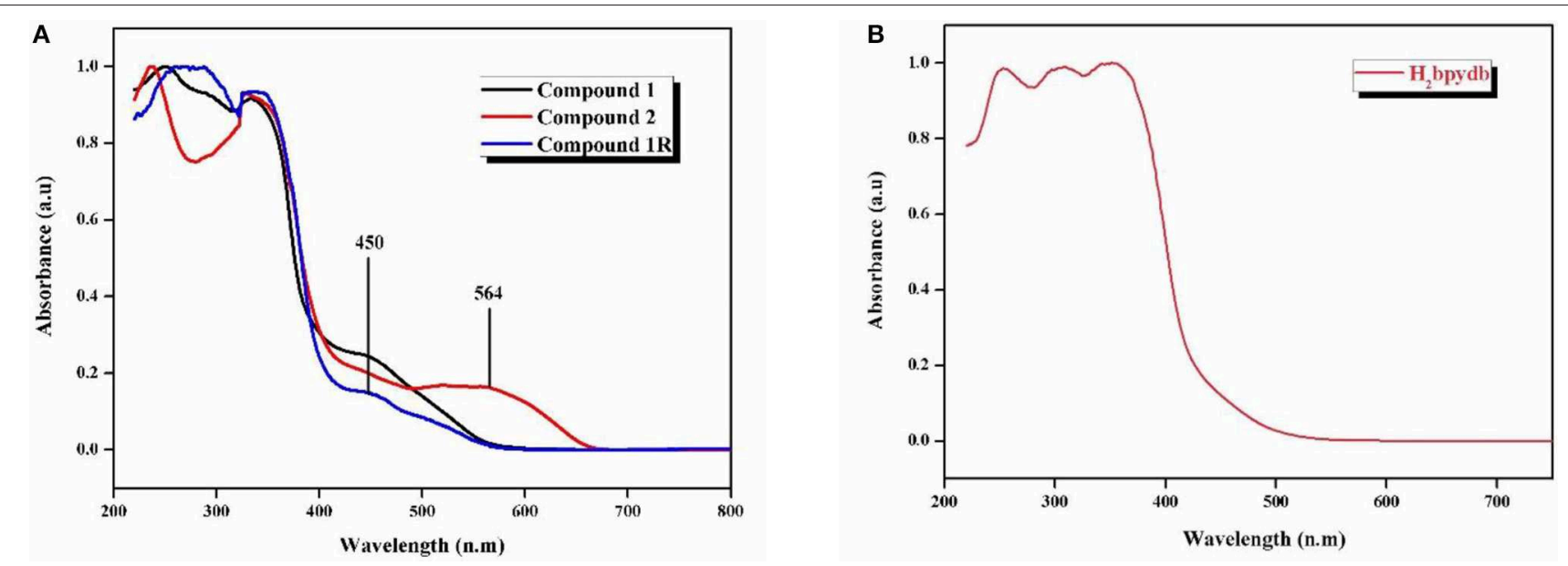

FIGURE 6 | Solid state-diffuse reflectance spectra (DRS) of (A) compounds $\mathbf{1}, \mathbf{2}$, and $\mathbf{1 R}$ and (B) $\mathrm{H}_{2}$ bpydb ligand.

(calcd. 3.05\%); in the second step, $\mathbf{1}$ and $\mathbf{1 R}$ loses lattice DMF molecules with weight loss of 23.4 and $24.6 \%$ respectively in the temperature range of $120-250^{\circ} \mathrm{C}$ (calcd. $25 \%$ ). On the other hand, compound $\mathbf{2}$ (prepared separately, as described in synthesis section) shows a single step degradation process (due to the absence of coordinated water molecules), in which the weight loss $(24.9 \%)$ in the temperature of $120-260^{\circ} \mathrm{C}$ is attributed to the loss of lattice DMF molecules (calcd. 25.6\%). The identical features of the TGA curve of regenerated 1R-crystalline phase to those of parent $\mathbf{1}$ crystals confirm the reversible conversion of compound $\mathbf{2}$ to its pristine $\mathbf{1}$. Beyond these temperatures, the compounds follow a significant weight loss corresponding to the decomposition of the organic part of the compound i.e., $\mathrm{H}_{2}$ bpydb.

\section{Electronic Spectra of Compounds 1, 2, and $1 R$}

The electronic absorption spectra of compounds $\mathbf{1}, \mathbf{2}$, and $\mathbf{1} \mathbf{R}$ along with the free ligand $\left(\mathrm{H}_{2}\right.$ bpydb) are recorded in the solid state on powdered samples. Figure 6 shows the normalized solid state UV-visible spectra (diffuse reflectance spectra) of all the compounds at room temperature. The compound $\mathbf{1}$ shows the absorption maxima $\left(\lambda_{\max }\right)$ at $248,290,334$, and $450 \mathrm{~nm}$, whereas compound 2, exhibits absorption maxima at 239,328 , and $564 \mathrm{~nm}$. In the case of regenerated compound 1R, the absorption peaks are observed at 256, 288, 337, and $450 \mathrm{~nm}$ (Figure 6A).

Thus, the solid state diffuse reflectance spectra (DRS) of 1 and 2 show that there is a red-shift in going from compound $1(450 \mathrm{~nm})$ to compound $2(564 \mathrm{~nm})$ by thermochromic conversion as shown in Figure 6. This red shift is consistent with the color change from orange (compound 1) to deep-purple (compound 2); this shift can be attributed to hexa-coordinated $\mathrm{Co}(\mathrm{II})$ in compound $\mathbf{1}$ to tetra-coordinated $\mathrm{Co}(\mathrm{II})$ in dehydrated compound 2. The regenerated compound $\mathbf{1 R}$ exhibits almost identical feature in its DRS spectrum to parent 1 (Figure 6).
This is consistent with its restoration of the orange color of parent $\mathbf{1}$.

The high energy bands in the case of all the three compounds are attributed to the intra-ligand charge transfer transitions due to their very close resemblance to those of free ligand, i.e., $\mathrm{H}_{2}$ bpydb ligand, which shows the $\lambda_{\max }$ values at 254,310 , and $353 \mathrm{~nm}$ (Figure 6B).

\section{CONCLUSION}

In conclusion, we designed and synthesized a $\mathrm{Co}$ (II)-coordination polymer, compound $\left\{\mathrm{Co}_{0.5}^{\text {II }}(\mathrm{Hbpydp})\left(\mathrm{H}_{2} \mathrm{O}\right)\right\}_{\mathbf{n}} \cdot \mathbf{2 n D M F}(\mathbf{1})$, based on the bifunctional ligand, i.e., $\mathrm{H}_{2}$ bpydb (4,4'-(4,4'-bipyridine-2,6-diyl)dibenzoic acid), under the hydrothermal conditions. The SCXRD analysis reveals that the compound $\mathbf{1}$ forms a two-dimensional network in its crystal structure containing $\left\{\mathrm{CoO}_{4} \mathrm{~N}_{2}\right\}$ octahedral core unit, formed by the coordination of two oxygen and two nitrogen atoms from four ligands and two oxygen atoms from two water molecules. The title compound $\mathbf{1}$ undergoes reversible color change from orange to deep-purple when heated under vacuum to form dehydrated compound $\left\{\mathrm{Co}_{0.5}^{\text {II }}(\mathrm{Hbpydp})\right\}_{\mathrm{n}} \cdot 2 n \mathrm{DMF}(2)$. This is due to the loss of coordinated water molecules leading to the transformation of octahedral coordination geometry around the $\mathrm{Co}$ (II) center (compound 1) to a tetra-coordinated $\mathrm{Co}$ (II) geometry (compound 2) resulting in different electronic absorption features of compound 2 rendering different colors to the pertinent compounds. The reversible nature of this conversion is observed when the dehydrated compound $\left\{\mathbf{C o}_{\mathbf{0 . 5}}^{\text {II }}(\mathbf{H b p y d p})\right\}_{\mathbf{n}} \cdot \mathbf{2 n D M F}$ (2) is immersed in water-DMF mixed solvent system to regenerate the original rehydrated crystalline compound 1R. Based on these studies, compound $\left[\mathrm{Co}_{0.5}^{\text {II }}(\mathrm{Hbpydp})\left(\mathrm{H}_{2} \mathrm{O}\right)\right]_{n} \cdot 2 n \mathrm{DMF}$ (1) can be described as a functional metal organic framework (MOF) containing compound exhibiting reversible crystal-to-amorphous-to-crystal (CAC) transformation. The thermal stability (TGA) of all the 
compounds is studied and we found that all the compounds are stable up to $150^{\circ} \mathrm{C}$, consistent with PXRD studies. The thermochromic behavior (reversible color change) of this system is demonstrated by electronic absorption spectroscopy.

\section{DATA AVAILABILITY}

The raw data supporting the conclusions of this manuscript will be made available by the authors, without undue reservation, to any qualified researcher.

\section{AUTHOR CONTRIBUTIONS}

SB synthesized and characterized the compounds, described in this manuscript under the supervision of SD. Both SB and SD analyzed the relevant data together. This manuscript has been written by SB and SD together.

\section{REFERENCES}

Bommakanti, S., Venkataramudu, U., and Das, S. K. (2019). Functional coordination polymers from a bifunctional ligand: a quantitative transmetalation via single crystal to single crystal transformation. Cryst. Growth Des. 19, 1155-1166. doi: 10.1021/acs.cgd.8b01635

Burneo, I., Stylianou, K. C., Rodríguez-Hermida, S., Juanhuix, J., Fontrodona, X., Imaz, I., et al. (2015). Two new adenine-based $\mathrm{Co}(\mathrm{II})$ coordination polymers: synthesis, crystal structure, coordination modes, and reversible hydrochromic behavior. Cryst. Growth Des. 15, 3182-3189. doi: 10.1021/acs.cgd.5b00218

Chughtai, A. H., Ahmad, N., Younus, H. A., Laypkov, A., and Verpoort, F. (2015). Metal-organic frameworks: versatile heterogeneous catalysts for efficient catalytic organic transformations. Chem. Soc. Rev. 44, 6804-6849. doi: $10.1039 / \mathrm{c} 4 \mathrm{cs} 00395 \mathrm{k}$

Dey, A., Garai, A., Gude, V., and Biradha, K. (2018). Thermochromic, solvatochromic, and piezochromic $\mathrm{Cd}(\mathrm{II})$ and $\mathrm{Zn}(\mathrm{II})$ coordination polymers: detection of small molecules by luminescence switching from blue to green. Cryst. Growth Des. 18, 6070-6077. doi: 10.1021/acs.cgd.8b00924

Dhakshinamoorthy, A., Opanasenko, M., Čejka, J., and Garcia, H. (2013). Metal organic frameworks as heterogeneous catalysts for the production of fine chemicals. Catal. Sci. Technol. 3, 2509-2540. doi: 10.1039/c3cy00350g

García-López, V., Orts-Mula, F. J., Palacios-Corella, M., Clemente-Juan, J. M., Clemente-León, M., and Coronado, E. (2018). Field-induced slow relaxation of magnetization in a mononuclear $\mathrm{Co}(\mathrm{II})$ complex of 2,6-bis(pyrazol-1yl)pyridine functionalized with a carboxylic acid. Polyhedron 150, 54-60. doi: 10.1016/j.poly.2018.05.006

He, H., Xue, Y. Q., Wang, S. Q., Zhu, Q. Q., Chen, J., Li, C. P., et al. (2018). A double-walled bimetal-organic framework for antibiotics sensing and size-selective catalysis. Inorg. Chem. 57, 15062-15068. doi: 10.1021 /acs.inorgchem. 8 b01898

Heering, C., Boldog, I., Vasylyeva, V., Sanchiz, J., and Janiak, C. (2013). Bifunctional pyrazolate-carboxylate ligands for isoreticular cobalt and zinc MOF-5 analogues with magnetic analysis of the $\{\mathrm{Co} 4(\mu 4-\mathrm{O})\}$ node. Cryst. Eng. Comm.15, 9757-9768. doi: 10.1039/c3ce41426d

Hirayama, T., Manako, T., and Imai, H. (2008). A metal coordination polymer for fuel cell applications: nanostructure control toward high performance electrocatalysis. E J. Surf. Sci. Nanotech. 6, 237-240. doi: 10.1380/ejssnt.2008.237

Hou, L., Zhang, W.-X., Zhang, J.-P., Xue, W., Zhang, Y.-B., and Chen, X.M. (2010). An octacobalt cluster based, $(3,12)$-connected, magnetic, porous coordination polymer. Chem. Commun. 46, 6311-6313. doi: $10.1039 / \mathrm{c} 0 \mathrm{cc} 01106 \mathrm{a}$

Hou, X.-Y., Wang, X., Li, S.-N., Jiang, Y.-C., Hu, M.-C., and Zhai, Q.-G. (2017). Gas uptake and supercapacitor performance of a highly connected porous

\section{FUNDING}

We thank SERB, DST, Government of India (Project EMR/2017/002971) for financial support. SB thanks CSIR, New Delhi for fellowship.

\section{ACKNOWLEDGMENTS}

We acknowledge Dr. Sathish K. Kurapati for helping in crystallography. Dr. Paulami Manna is gratefully acknowledged for her helpful discussions.

\section{SUPPLEMENTARY MATERIAL}

The Supplementary Material for this article can be found online at: https://www.frontiersin.org/articles/10.3389/fmats. 2019.00170/full\#supplementary-material

Co-metal-organic framework induced by ligand bulk. Cryst. Growth Des. 17, 3229-3235. doi: 10.1021/acs.cgd.7b00215

Hu, K.-Q., Wu, Q.-Y., Mei, L., Zhang, X.-L., Ma, L., Song, G., et al. (2017). Novel viologen derivative based uranyl coordination polymers featuring photochromic behaviors. Chem. Eur. J. 23, 18074-18083. doi: 10.1002/chem.201704478

Hu, P., Yin, L., Kirchon, A., Li, J., Li, B., Wang, Z., et al. (2018). Magnetic metalorganic framework exhibiting quick and selective solvatochromic behavior along with reversible crystal-to-amorphous-to-crystal transformation. Inorg. Chem. 57, 7006-7014. doi: 10.1021/acs.inorgchem.8b00703

Kim, M., Boissonnault, J. A., Dau, P. V., and Cohen, S. M. (2011). Metal-organic framework regioisomers based on bifunctional ligands. Angew. Chem. Inter. Ed. 50, 12193-12196. doi: 10.1002/anie.201106429

Kreno, L. E., Leong, K., Farha, O. K., Allendorf, M., Van Duyne, R. P., and Hupp, J. T. (2012). Metal-organic framework materials as chemical sensors. Chem. Rev. 112, 1105-1125. doi: 10.1021/cr200324t

Kundu, T., Jana, A. K., and Natarajan, S. (2014). Stepwise crystallization: illustrative examples of the use of metalloligands [Cu6(mna)6]6- and [Ag6(Hmna)2(mna)4]4- (H2mna = 2-mercapto nicotinic acid) in the formation of heterometallic two- and three-dimensional assemblies with brucite, pcu, and sql Topologies. Cryst. Growth Des. 14, 4531-4544. doi: $10.1021 / \operatorname{cg} 500632 \mathrm{~d}$

Lim, K. S., Song, J. H., Kang, D. W., Kang, M., Eom, S., Koh, E. K., et al. (2018). Reversible crystal-to-amorphous structural transformations and magnetic variations in single end-on azide-bridged $\mathrm{M}(\mathrm{II})(\mathrm{M}=\mathrm{Mn}, \mathrm{Ni})$ coordination polymers. Dalton Trans. 47, 845-851. doi: 10.1039/c7dt03886k

Liu, J., and Li, J. (2019). Chromism of three complexes derived from 1-butyl4,4'-bipyridinium ligand and 1,3,5-benzenetricarboxylic acid. Polyhedron 161, 231-236. doi: 10.1016/j.poly.2019.01.011

Lu, Z.-Z., Zhang, R., Li, Y.-Z., Guo, Z.-J., and Zheng, H.-G. (2011). Solvatochromic behavior of a nanotubular metal-organic framework for sensing small molecules. J. Am. Chem. Soc.133, 4172-4174. doi: 10.1021/ja109437d

Manna, P., Debgupta, J., Bose, S., and Das, S. K. (2016). A mononuclear Co(II) coordination complex locked in a confined space and acting as an electrochemical water-oxidation catalyst: a "Ship-in-a-Bottle" approach. Angew. Chem. Inter. Ed. 55, 2425-2430. doi: 10.1002/anie. 201509643

Mehlana, G., Bourne, S. A., Ramon, G., and Öhrström, L. (2013). Concomitant metal organic frameworks of Cobalt(II) and 3-(4-Pyridyl)benzoate: optimized synthetic conditions of solvatochromic and thermochromic systems. Cryst. Growth Des. 13, 633-644. doi: 10.1021/cg301312v

Mínguez Espallargas, G., and Coronado, E. (2018). Magnetic functionalities in MOFs: from the framework to the pore. Chem. Soc. Rev. 47, 533-557. doi: $10.1039 / \mathrm{c} 7 \mathrm{cs} 00653 \mathrm{e}$ 
Mondal, P., Dey, B., Roy, S., Bera, S. P., Nasani, R., Santra, A., et al. (2018). Field-induced slow magnetic relaxation and anion/solvent dependent proton conduction in Cobalt(II) coordination polymers. Cryst. Growth Des. 18, 6211-6220. doi: 10.1021/acs.cgd.8b01080

Pardo, R., Zayat, M., and Levy, D. (2011). Photochromic organic-inorganic hybrid materials. Chem. Soc. Rev. 40, 672-687. doi: 10.1039/c0cs00065e

Rajput, L., and Biradha, K. (2011). Crystalline forms of 1,3,5-benzenetri(pyridinyl)carboxamides: isolated site hydrates as polymorphs and solvates. J. Mol. Struct. 991, 97-102. doi: 10.1016/j.molstruc.2011.02.011

Ren, Y., Chia, G. H., and Gao, Z. (2013). Metal-organic frameworks in fuel cell technologies. Nano Today. 8, 577-597. doi: 10.1016/j.nantod.2013. 11.004

Ryu, D. W., Lee, W. R., Lee, J. W., Yoon, J. H., Kim, H. C., Koh, E. K., et al. (2010). Magnetic metal-organic framework constructed from a paramagnetic metalloligand exhibiting a significant sorption and reversible magnetic conversions. Chem. Commun. 46, 8779-8781. doi: 10.1039/ c0cc03540h

Sharma, M. K., Senkovska, I., Kaskel, S., and Bharadwaj, P. K. (2011). Threedimensional porous $\mathrm{Cd}(\mathrm{II})$ coordination polymer with large one-dimensional hexagonal channels: high pressure $\mathrm{CH}_{4}$ and $\mathrm{H}_{2}$ adsorption studies. Inorg. Chem. 50, 539-544. doi: 10.1021/ic101412p

Sheldrick, G. M. (1997). SADABS: Program for Absorption Correction. Gottingen: University of Gottingen.

Sheldrick, G. M. (2015a). Crystal structure refinement with SHELXL. Acta Cryst.C71, 3-8. doi: 10.1107/s2053229614024218

Sheldrick, G. M. (2015b). SHELXT - Integrated space-group and crystal-structure determination. Acta Cryst. A71, 3-8. doi: 10.1107/s2053273314026370

Song, S.-Y., Song, X.-Z., Zhao, S.-N., Qin, C., Su, S.-Q., Zhu, M., et al. (2012). Syntheses, structures and physical properties of transition metal-organic frameworks assembled from trigonal heterofunctional ligands. Dalton Trans. 41, 10412-10421. doi: 10.1039/c2dt30826f

Stavila, V., Talin, A. A., and Allendorf, M. D. (2014). MOF-based electronic and opto-electronic devices. Chem. Soc. Rev. 43, 5994-6010. doi: $10.1039 / \mathrm{c} 4 \mathrm{cs} 00096 \mathrm{j}$

Sun, Y., Song, E., and Wang, D. (2013). Poly[[diaqua-bis-\{ $\mu-4-[6-(4-c a r b-$ oxy-phen-yl)-4,4'-bipyridin-2-yl]benzoato- $\mathrm{k}(2) \quad \mathrm{O}$ :N (1')\}copper(II)] dimethyl-formamide tetra-solvate]. Acta Cryst. 69, m202-m203. doi: $10.1107 / S 1600536813006430$
Tandekar, K., Garai, S., and Supriya, S. (2018). A reversible redox reaction in a keggin polyoxometalate crystal driven by visible light: a programmable solid-state photochromic switch. Chem. Eur. J. 24, 9747-9753. doi: 10.1002/chem.201801126

Thapa, K. B., Wu, M.-H., Yang, X.-K., Chen, T.-R., and Chen, J.-D. (2018). Co(II) coordination polymers exhibiting reversible structural transformation and color change: a comparative analysis with $\mathrm{Ni}(\mathrm{II})$ analogue. Polyhedron 152 , 225-232. doi: 10.1016/j.poly.2018.06.042

Tian, C.-B., Chen, R.-P., He, C., Li, W.-J., Wei, Q., Zhang, X.-D., et al. (2014). Reversible crystal-to-amorphous-to-crystal phase transition and a large magnetocaloric effect in a spongelike metal organic framework material. Chem. Commun. 50, 1915-1917. doi: 10.1039/c3cc48325h

Toma, O., Mercier, N., Allain, M., Kassiba, A. A., Bellat, J.-P., Weber, G., et al. (2015). Photo- and thermochromic and adsorption properties of porous coordination polymers based on bipyridinium carboxylate ligands. Inorg. Chem. 54, 8923-8930. doi: 10.1021/acs.inorgchem.5b00975

Wan, F., Qiu, L.-X., Zhou, L.-L., Sun, Y.-Q., and You, Y. (2015). A fluorescent, photochromic and thermochromic trifunctional material based on a layered metal-viologen complex. Dalton Trans. 44, 18320-18323. doi: $10.1039 / \mathrm{c} 5 \mathrm{dt} 03405 \mathrm{a}$

Wei, Y.-S., Chen, K.-J., Liao, P.-Q., Zhu, B.-Y., Lin, R.-B., Zhou, H.-L., et al. (2013). Turning on the flexibility of isoreticular porous coordination frameworks for drastically tunable framework breathing and thermal expansion. Chem. Sci. 4, 1539-1546. doi: 10.1039/c3sc22222e

Zhang, C., Sun, L., Zhang, C., Wan, S., Liang, Z., and Li, J. (2016). Novel photoand/or thermochromic MOFs derived from bipyridinium carboxylate ligands. Inorg. Chem. Front. 3, 814-820. doi: 10.1039/c6qi00013d

Conflict of Interest Statement: The authors declare that the research was conducted in the absence of any commercial or financial relationships that could be construed as a potential conflict of interest.

Copyright () 2019 Bommakanti and Das. This is an open-access article distributed under the terms of the Creative Commons Attribution License (CC BY). The use, distribution or reproduction in other forums is permitted, provided the original author(s) and the copyright owner(s) are credited and that the original publication in this journal is cited, in accordance with accepted academic practice. No use, distribution or reproduction is permitted which does not comply with these terms. 